\title{
The involvement of two epoxide hydrolase genes, NbEH1.1 and NbEH1.2, of Nicotiana benthamiana in the interaction with Colletotrichum destructivum, Colletotrichum orbiculare or Pseudomonas syringae pv. tabaci
}

\author{
C. P. Wijekoon ${ }^{\mathrm{A}}$, P. H. Goodwin ${ }^{\mathrm{A}, \mathrm{B}}$ and T. Hsiang ${ }^{\mathrm{A}}$ \\ ADepartment of Environmental Biology, University of Guelph, Guelph, Ontario N1G 2W1, Canada. \\ ${ }^{\mathrm{B} C}$ Corresponding author. Email: pgoodwin@uoguelph.ca
}

\begin{abstract}
Epoxide hydrolase hydrates epoxides to vicinal diols in the phyto-oxylipin peroxygenase pathway resulting in the production of epoxy alcohols, dihydrodiols, triols and epoxides, including many lipid epoxides associated with resistance. Two epoxide hydrolase genes from Nicotiana benthamiana L., NbEH1.1 and NbEH1.2, were amplified from coding DNA of leaves during a susceptible response to the hemibiotrophic pathogens, Colletotrichum destructivum O' Gara, Colletotrichum orbiculare Berk. and Mont. von Arx. or Pseudomonas syringae pv. tabaci Wolf and Foster, or the hypersensitive resistance response to $P$. syringae pv. tabaci expressing avrPto. Increases in expression of $N b E H 1.1$ generally occurred during the late biotrophic and necrotrophic stages in the susceptible responses and before the hypersensitive response. NbEH1.2 expression was not significantly induced by $C$. orbiculare but was induced by $C$. destructivum, $P$. syringae pv. tabaci and $P$. syringae pv. tabaci expressing avrPto, although to a lesser degree than $N b E H 1.1$. Virus-induced gene silencing of $\mathrm{NbEH1.1}$ delayed the appearance of lesions for $C$. destructivum, reduced populations of $P$. syringae pv. tabaci and increased populations of $P$. syringae pv. tabaci expressing avrPto. The importance of epoxide hydrolase during pathogen attack may be related to its roles in detoxification, signalling, or metabolism of antimicrobial compounds.
\end{abstract}

Additional keywords: hemibiotrophy, hypersensitive response, oxylipin, virus-induced gene silencing.

\section{Introduction}

In plants, phyto-oxylipins are synthesised by the lipoxygenase pathway, where oxygen is incorporated into the fatty acids, linoleic or linolenic acid, to create hydroperoxides (Blee 1998, 2002). These hydroperoxides can enter the hydroxyperoxide lyase pathway to produce traumatin (a wound hormone), allene oxide synthase pathway to produce jasmonic acid (a signalling molecule) or peroxygenase pathway to produce epoxides, epoxy alcohols, dihydrodiols and triols. Epoxide hydrolase $(\mathrm{EH})$ is the second enzyme in the peroxygenase pathway hydrating epoxides to vicinal diols. EHs are present in all organisms and belong to a sub-category of hydrolytic enzymes that include esterases, proteases, dehalogenases and lipases (Beetham et al. 1995).

In animals, the products of EH have many different activities, such as regulation of inflammation, xenobiotic detoxification and drug metabolism (Newman et al. 2005). Plant EHs appear to play a role in the biosynthesis of monomers of cutin, a polymer that accumulates in cell walls of damaged tissues (Blee 1998). Cutin is important in plant development, protection from environmental stresses and disease resistance. Plant EHs may also contribute to disease resistance by producing oxylipin phytoalexins (Ohta et al. 1991; Hamberg and Hamberg 1996). Phytoalexins are pathogeninduced low-molecular-weight antimicrobial compounds often associated with the hypersensitive response (HR) and other defences (Hammerschmidt 1999). Plant oxylipins have antimicrobial activity against a wide range of plant pathogenic bacteria and fungi (Prost et al. 2005). In addition, epoxides are usually unstable and reactive causing toxicity to cells, and thus another role for EHs in plants would be to break down epoxides accumulating during stress into more stable and less reactive compounds (Murray et al. 1993).

NtEH-1, an EH gene from Nicotiana tabacum L., has been the subject of several studies. Its induction was associated with HR to tobacco mosaic virus (TMV), and it was believed to be involved in affecting signalling of resistance or detoxifying compounds produced during the oxidative burst of the HR (Guo et al. 1998). For tobacco inoculated with different bacteria, increased $N t E H-1$ expression was associated with the HR as well as basal resistance, which is not associated with the HR (Szatmari et al. 2006). Increased NtEH-1 expression, along with that of several other genes, was also associated with stress resistance produced by sublethal doses of the redox-active compound, methyl viologen, and $\mathrm{EH}$ activity was presumed to be involved in detoxification (Vranová et al. 2002). NtEH-1 was also among a group of genes induced in BY-2 cell cultures going into the stationary growth phase, and the enzyme was hypothesised to be involved in the response to extracellular signals (Matsuoka et al. 2004). Although these studies indicate that NtEH-1 may be involved in detoxification, signalling, HR 
and basal disease resistance, these conclusions have thus far been based only on examinations of $\mathrm{NtEH}-\mathrm{l}$ expression.

A close relative of $N$. tabacum is Nicotiana benthamiana L., which has been proposed to be a model plant for studying gene function by virus-induced silencing (VIGS) (Baulcombe 1999, 2004). VIGS can silence genes in mature plants in 10-20 days after inoculation with a recombinant virus, does not require stable plant transformation, can silence one or more genes at a time, and does not need a full length clone of the targeted gene to be silenced (Robertson 2004). Examples of the use of VIGS in the study of genes associated with diseases of $N$. benthamiana include examinations of $\mathrm{N}$-mediated signalling resistance to TMV (Liu et al. 2002), glutathione S-transferases in the susceptibility to Colletotrichum orbiculare and Colletotrichum destructivum (Dean et al. 2002) and cysteine proteinases in the susceptibility to $C$. destructivum and HR resistance to Pseudomonas syringae pv. tomato (Hao et al. 2006).

Because of the potential importance of $N t E H-1$ in disease resistance, the goal of this research was to find a homologue of $N t E H-1$ in $N$. benthamiana, examine its response to fungal and bacterial infection, and then silence the gene through VIGS using a tobacco rattle virus (TRV)-based vector to assess its role in resistance and susceptibility. The susceptible responses of $N$. benthamiana that were investigated were anthracnose caused by the hemibiotrophic fungi, $C$. destructivum and C. orbiculare (Shen et al. 2001a, 2001b), and wildfire caused by the hemibiotrophic bacterium, Pseudomonas syringae pv. tabaci (Lucas 1965). In addition, a resistance response was examined in $N$. benthamiana expressing the resistance gene, Pto, which induces a HR when it interacts with $P$. syringae pv. tabaci expressing a type III secretion system effector encoded by avrPto (Rommens et al. 1995).

\section{Materials and methods \\ Biological materials}

Wild type and Pto-transformed (Rommens et al.1995) Nicotiana benthamiana $\mathrm{L}$. were grown to the eighth true-leaf stage with $16 \mathrm{~h}$ light $\left(150 \mu \mathrm{mol} \mathrm{m} \mathrm{m}^{-2} \mathrm{~s}^{-1}\right)$ at $25^{\circ} \mathrm{C}$ and $8 \mathrm{~h}$ dark at $17^{\circ} \mathrm{C}$. Strain N150P3 of Colletotrichum destructivum O' Gara and ATCC20767P1 of Colletotrichum orbiculare Berk. and Mont. von Arx (Chen et al. 2003) were cultured on sodium-chlorideyeast-extract- sucrose-agar medium (SYAS) (Manandhar et al. 1986) at $22^{\circ} \mathrm{C}$ under continuous fluorescent light. Conidia were washed from 7-12 day-old plates, and plants were sprayed with a suspension of $10^{5}$ conidia $\mathrm{mL}^{-1}$ for $C$. destructivum and $2 \times 10^{6}$ conidia $\mathrm{mL}^{-1}$ for $C$. orbiculare, and then incubated at room temperature in containers to maintain high humidity. The lesion number was counted, and the area of each leaf was measured using a leaf area meter (Model 3100; LI-COR, Lincoln, NB, USA) to calculate lesions per $\mathrm{cm}^{2}$ leaf.

Pseudomonas syringae pv. tabaci Wolf and Foster was grown overnight in King's medium B (KB; King et al. 1954) at $22^{\circ} \mathrm{C}$. A suspension of $10^{6}$ colony forming units (CFU) $\mathrm{mL}^{-1}$ for $P$. syringae pv. tabaci $11528 \mathrm{R}$ or $10^{8} \mathrm{CFU} \mathrm{mL}^{-1}$ for P. syringae pv. tabaci containing avrPto in $10 \mathrm{~mm} \mathrm{MgCl}_{2}$ was infiltrated with a needle-less syringe into each of the two youngest fully developed leaves of wild type or Pto-transformed $N$. benthamiana, respectively. After incubation at $16 \mathrm{~h}$ light $\left(150 \mu \mathrm{mol} \mathrm{m}{ }^{-2} \mathrm{~s}^{-1}\right)$ at $25^{\circ} \mathrm{C}$ and $8 \mathrm{~h}$ dark at $17^{\circ} \mathrm{C}, 0.785 \mathrm{~cm}^{2}$ leaf discs were excised, ground in $1 \mathrm{~mL} 10 \mathrm{mM} \mathrm{MgCl}_{2}$, serially diluted in $10 \mathrm{mM} \mathrm{MgCl}_{2}$ and then plated onto $\mathrm{KB}$ agar. Bacterial populations were assessed as CFU per $\mathrm{cm}^{2}$ leaf.

\section{Sequence alignments}

EH protein sequences from members of the Solanaceae were obtained from the Dana Farber Cancer Institute (DFCI) Gene Indices (http://compbio.dfci.harvard.edu/, accessed 10 July 2007) by a keyword search for epoxide hydrolase, and are listed in Table 1. The sequences were aligned with CLUSTALX (Chenna

Table 1. Source, accession number and gene name of epoxide hydrolase predicted protein sequences from members of the Solanaceae with at least 100 amino acid length

\begin{tabular}{|c|c|c|}
\hline Source & Accession number ${ }^{\mathrm{A}}$ & Gene name \\
\hline Capsicum annuиm $\mathrm{L}$. & TC3801 & ${ }_{-} \mathrm{C}$ \\
\hline C. аппиит & TC3802 & - \\
\hline C. аппиит & TC4755 & - \\
\hline C. аппиит & TC5349 & - \\
\hline C. аппиит & TC5838 & - \\
\hline Lycopersicon esculentum $\mathrm{L}$. & TC178498 & - \\
\hline L. esculentum & TC174348 & - \\
\hline L. esculentum & TC186942 & - \\
\hline L. esculentum & TC170114 & - \\
\hline L. esculentum & $\mathrm{TC} 171270$ & - \\
\hline L. esculentum & TC171911 & - \\
\hline L. esculentum & TC186355 & - \\
\hline L. esculentum & TC190171 & - \\
\hline L. esculentum & TC185647 & - \\
\hline L. esculentum & TC181374 & - \\
\hline Nicotiana benthamiana L. & EU700053 & $\mathrm{NbEH1.1}$ \\
\hline$N$. benthamiana & ТC9495 & $\mathrm{NbEH1.2}$ \\
\hline N. benthamiana & EU779658 & $\mathrm{NbEH} 2.1$ \\
\hline$N$. benthamiana & EU779659 & $\mathrm{NbEH} 2.2$ \\
\hline Nicotiana tabacum L. & TC7691 & $\mathrm{NtEH}-1$ \\
\hline N. tabacum & TC7022 & - \\
\hline N. tabacum & TC4399 & - \\
\hline Solanum tuberosum L. & AAA81893 & StEH9.2 \\
\hline S. tuberosum & AAA81891 & StEH5.3 \\
\hline S. tuberosum & TC149040 & - \\
\hline S. tuberosum & TC150343 & - \\
\hline S. tuberosum & TC141127 & - \\
\hline S. tuberosum & TC144147 & - \\
\hline S. tuberosum & TC139523 & - \\
\hline S. tuberosum & TC132944 & - \\
\hline S. tuberosum & TC152206 & - \\
\hline S. tuberosum & TC146241 & - \\
\hline S. tuberosum & TC134015 & - \\
\hline S. tuberosum & TC156302 & - \\
\hline S. tuberosum & TC153402 & - \\
\hline S. tuberosum & TC155598 & - \\
\hline S. tuberosum & TC145540 & - \\
\hline S. tuberosum & TC152273 & - \\
\hline S. tuberosum & TC137677 & - \\
\hline S. tuberosum & TC150329 & - \\
\hline
\end{tabular}

${ }^{\mathrm{A}}$ Tentative consensus (TC) sequences were obtained from the DFCI Gene Indices (http://compbio.dfci.harvard.edu/). Other sequences were obtained from GenBank (www.ncbi.nlm.nih.gov/).

${ }^{\mathrm{B}} \mathrm{TC} 1982$ was separated into two genes: EU779658 and EU779659.

${ }^{\mathrm{C}}$ None provided. 
et al. 2003) using default parameters, and a dendrogram was generated using the neighbour-joining algorithm with 1000 bootstrap replications in CLUSTALX.

\section{3 'rapid amplification of CDNA ends (RACE) PCR}

Based on the grouping observed in a dendrogram of $\mathrm{EH}$ sequences, the following nucleotide sequences were chosen: N. benthamiana (TC9495), Solanum tuberosum L. (TC137677, TC144147 and TC139523), Lycopersicon esculentum L. (TC170114), Capsicum annuum (TC3801, TC3802 and TC4755) and Nicotiana tabacum L. (TC7691). These sequences were aligned in CLUSTALX, and conserved regions were used to design a forward $3^{\prime}$ RACE primer, NbEH1RACE (5'-TCCGAACWGCATTGCAGGT-3'). Primer specifications and suitability were tested using the program GeneRunner (Hastings Software, Hastings, NY, USA).

For all RNA extractions, leaf samples were immediately frozen in liquid nitrogen at $0-96 \mathrm{~h}$ post inoculation (HPI) for C. destructivum and Pseudomonas syringae pv. tabaci, 0-120 HPI for C. orbiculare, and 0-24 HPI for P. syringae pv. tabaci expressing avrPto. Samples were stored at $-80^{\circ} \mathrm{C}$. RNA extraction was done as per Hao et al. (2006). The RNA was resuspended in 25-50 $\mu \mathrm{L}$ DEPC-treated $\mathrm{dH}_{2} \mathrm{O}$ and stored at $-80^{\circ} \mathrm{C}$. Single-stranded coding DNA (cDNA) was synthesised from RNA using $3^{\prime}$ RACE oligo dT-anchor primer (5'-GACCAC GCGTATCGATGTCGACTTTTTTTTTTTTTTTTV-3') $(\mathrm{V}=\mathrm{A}$, $\mathrm{C}$ or $\mathrm{G}$ ) following the manufacturer's instructions (Roche, Indianapolis, IN, USA). All PCRs were performed using a Touchgene Thermo Cycler (Techne, Princeton, NJ, USA). PCR was done in $15 \mu \mathrm{L}$ with $2 \mu \mathrm{L}$ cDNA, 0.75 units $T s g$ polymerase (Biobasic, Markham, ON, CA), 10× Tsg polymerase buffer, $2 \mathrm{~mm}$ dNTPs, $2.5 \mathrm{~mm} \mathrm{MgSO}_{4}, 1.0 \mathrm{~mm}$ $\mathrm{NbEH} 1 \mathrm{RACE}$ primer and $1.0 \mathrm{~mm} 3^{\prime} \mathrm{RACE}$ anchor primer (5'-GACCACGCGTATCGATGTCGAC-3') supplied in the $5^{\prime} / 3^{\prime}$ RACE kit (Roche). Amplification was done at $94^{\circ} \mathrm{C}$ for $3 \mathrm{~min}$ followed by 30 cycles of $94^{\circ} \mathrm{C}$ for $30 \mathrm{~s}, 60^{\circ} \mathrm{C}$ for $1 \mathrm{~min}$, and $72^{\circ} \mathrm{C}$ for $1 \mathrm{~min}$ and a final $10 \mathrm{~min}$ at $72^{\circ} \mathrm{C}$. A PCR product was excised after electrophoresis in 1.2\% TAE agarose gels, purified with the GENECLEAN II Kit (Q BIOgene, Montreal, Quebec, Canada) and sequenced at Laboratory Services Division, (University of Guelph, Guelph, Ontario, Canada).

\section{Relative reverse transcription ( $R T)-P C R$}

Relative RT-PCR was done following Dean et al. (2002). Singlestranded cDNA was synthesised using Moloney Murine Leukemia Virus reverse transcriptase (Invitrogen, Burlington, Ontario, Canada) and oligo (dT) primer (Promega, Madison, WI, USA) using total RNA following the manufacturer's instructions.

A forward primer NbEH1F1 (5'-AGTAGCGGATGCAGGA TTTC- $3^{\prime}$ ) was designed in a conserved region among the EH genes that had been used to design primer NbEH1RACE, and it was predicted to be $504 \mathrm{bp}$ upstream of NbEH1RACE. This was paired with the gene-specific reverse primer NbEH1.1R1 (5'-TCTTTCACCATTCCACTT-3') designed from the $3^{\prime}$ UTR of the $3^{\prime}$ RACE product (designated NbEH1.1), or the genespecific reverse primer NbEH1.2R1 (5'-CTTATTTGAATA CTATGGTAGG-3') designed from the $3^{\prime}$ UTR of TC9495

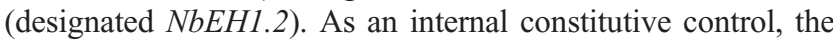

translation elongation factor $1 \alpha(N b E F 1 \alpha)$ forward primer, TobefS (5'-CTCCAAGGCTAGGTATGATG- $\left.3^{\prime}\right)$ and reverse primer, TobefA (5'-CTTCGTGGTTGCATCTCAAC-3') were used to obtain a $370 \mathrm{bp}$ RT-PCR product (Dean et al. 2002). The choice of $N b E F l \alpha$ was made as Dean et al. (2002) had shown that the expression of $N b E F 1 \alpha$ was constitutively expressed in infected leaves, and Nicot et al. (2005) had demonstrated that the translation elongation factor $1-\alpha$ gene in another solanaceous plant, potato, was the most stable among seven different housekeeping genes examined during biotic and abiotic stresses.

Relative RT-PCR was done in $15 \mu \mathrm{L}$ with $2 \mu \mathrm{L}$ cDNA, 0.75 units $T_{s} g$ polymerase (Biobasic), $10 \times T s g$ polymerase buffer, $2 \mathrm{~mm}$ dNTPs, $2.5 \mathrm{~mm} \mathrm{Mg}^{2+}, 0.5 \mathrm{~mm}$ TobefS, $0.5 \mathrm{~mm}$ TobefA, and $1.0 \mathrm{~mm}$ of each $\mathrm{EH}$ primer described above. Amplification was done at $94^{\circ} \mathrm{C}$ for $3 \mathrm{~min}$ followed by 35 cycles of $94^{\circ} \mathrm{C}$ for $30 \mathrm{~s}$, $60^{\circ} \mathrm{C}$ for $1 \mathrm{~min}$, and $72^{\circ} \mathrm{C}$ for $1 \mathrm{~min}$ and a final $10 \mathrm{~min}$ at $72^{\circ} \mathrm{C}$. RT-PCR products were separated in $1.2 \%$ TAE agarose gels, and the images were scanned and saved as TIFF files. The band intensities were determined for both the EH and EF1 $\alpha$ RT-PCR products using NIH Image (Scion Corporation, Frederick, MD, USA), and the ratio of band intensities was calculated for each gel lane. For all RT-PCR quantifications, at least four replications were done using two different RNA samples from two independent inoculations.

To confirm that the number of cycles was not excessive for quantification, relative RT-PCR was also done as above with 30 cycles, and the expression patterns were compared with those obtained with 35 cycles. No significant differences were found. To confirm the identity of the RT-PCR products, the bands for NbEH1.1 and NbEH1.2 at 48 HPI with P. syringae pv. tabaci were excised, purified and sequenced as described previously.

\section{Virus induced gene silencing (VIGS)}

The 3' RACE product was cloned into pGEMT-easy (MBI Fermentas, Burlington, Ontario, Canada), and then digested with EcoR1 for subcloning into the EcoR1 site of pTRV2 (Dinesh-Kumar et al. 2003). The construct was transformed into Escherichia coli DH5 $\alpha$, and selected on Luria Broth (LB) agar containing $50 \mathrm{mg} \mathrm{L}^{-1}$ kanamycin. The plasmid was extracted from E. coli and electroporated into Agrobacterium tumefaciens strain GV3101. Colonies growing on LB agar amended with $50 \mathrm{mg} \mathrm{L}^{-1}$ kanamycin and $5 \mathrm{mg} \mathrm{L}^{-1}$ tetracycline were screened for inserts with NbEH1RACE primer and $3^{\prime}$ RACE anchor primer (Roche) using the $3^{\prime}$ RACE PCR conditions described above.

Cultures of $A$. tumefaciens containing either pTRV2 with the 3' RACE product of NbEH1.1 or pTRV2 with the green fluorescent protein gene (GFP) from pEZS-CL (Yoshimoto et al. 2004) as a vector control were grown at $28^{\circ} \mathrm{C}$ for $48 \mathrm{~h}$ on $\mathrm{LB}$ agar containing kanamycin and tetracycline. Infiltration of the two first fully matured leaves of three (for relative gene expression) or eight (for disease assessment) plants at the fourth true-leaf stage was done with equal numbers of A. tumefaciens cells containing pTRV-RNA1 with either pTRV2-NbEH1.1 or pTRV2-GFP as described by Liu et al. (2002). As an additional control, an equal number of plants were also infiltrated with $10 \mathrm{~mm} \mathrm{MgCl}_{2}$. A repeated 
experiment was done for disease assessment, and two more repeated experiments were done for relative RT-PCR.

At 14-15 days after A. tumefaciens inoculation, the plants were inoculated with $C$. destructivum, $C$. orbiculare or P. syringae pv. tabaci as described above. Disease severity and relative RT-PCR was assessed after fungal or bacterial inoculation on the first fully mature leaves as described above. Disease severity was assessed at 64-96 HPI for $C$. destructivum, C. orbiculare or $P$. syringae pv. tabaci, and assessed at $12 \mathrm{HPI}$ for P. syringae pv. tabaci containing avrPto.

\section{Statistical analysis}

Data analysis of the relative RT-PCR results from silencing of $\mathrm{NbEH1.1}$ and analysis of the disease assessment in $\mathrm{MgCl}_{2}$ control, TRV vector control and the NbEH1.1-silenced plants was done using PROC GLM (analysis of variance) as implemented in SAS (SAS Institute, Cary, NC, USA). Analysis of variance was conducted to look for a significant $(P<0.05)$ interaction between the main treatment effect (e.g. gene expression or disease severity) and experimental repetition. If the interaction term was not significant, then the data for all three repeated experiments were combined for statistical analyses. Where significant treatment effects were found $(P<0.05)$, the means were separated by the test of LSD at $P=0.05$.

\section{Results}

\section{$\mathrm{NbEH1.1}$ amplification and sequence analysis}

An alignment was made of EH nucleotide (nt) sequences from plants in the Solanaceae in the DFCI Gene Indices (http:// compbio.dfci.harvard.edu/, accessed 10 July 2007) showing the highest identity to NTEH-1. The sequences were from N. tabacum $($ NtEH-1=TC7691), N. benthamiana (TC9495), C. annuum (TC3801, TC3802 and TC4755), S. tuberosum (TC144147 and TC139523) and L. esculentum (TC170114) (Table 1). A highly conserved region in the sequences was used to design the primer NBEH1RACE, which was paired with a $3^{\prime}$ RACE anchor primer to amplify a single RT-PCR product of $490 \mathrm{bp}$ from cDNA of $N$. benthamiana leaves at $72 \mathrm{HPI}$ with $P$. syringae pv. tabaci. This sampling time was chosen as preliminary results indicated that it was the time after infection when the strongest band could be obtained using those primers. The sequence of the $3^{\prime}$ RACE PCR product had $96 \%$ nt identity with NTEH-1 in contrast to only $51 \%$ nt identity with TC9495 from $N$. benthamiana. This novel EH gene was designated NbEH1.1 and TC9495 was designated NbEH1.2.

A forward primer (NbEH1F1) was designed in a conserved region among the $N t E H-l$ homologues, and paired with a reverse primer (NbEH1R1) designed in a region of the $3^{\prime}$ UTR of NbEH1.1 that differed from NbEH1.2. RT-PCR with primers NbEH1F1 and NbEH1R1 resulted in a 657 bp band using cDNA from the 72 HPI interaction with $P$. syringae pv. tabaci. The sequence had a 52 bp overlap with $100 \%$ nt identity to the $3^{\prime}$ RACE sequence of $N b E H 1.1$. Joining the two sequences resulted in a contig of $1012 \mathrm{bp}$ for $\mathrm{NbEH1.1}$.

\section{Epoxide hydrolase sequence comparison}

A comparison was made of the predicted protein sequences of NbEH1.1 and 39 other EHs from plants in the Solanaceae
(Table 1). The EH sequences formed two major clades, which were named EH1 and EH2 (Fig. 1). Within the EH1 clade, there were two subclusters, A and B, with high and low bootstrap support ( $85 \%$ and $51 \%$, respectively), while the EH2 clade had moderate bootstrap support (61\%). Both NbEH1.1 and NbEH1.2 were in subcluster A in the EH1 clade. A BLASTN search of the DFCI $N$. benthamiana Gene Index (Release 2.0, http://compbio. dfci.harvard.edu/) with $\mathrm{NbEH1.1}$ as the query sequence revealed a more distantly related EH sequence, TC1982; however, a closer examination of the 10 EST sequences comprising TC1982 showed that it was composed of at least two related genes rather than a single gene. These two EH genes were designated NbEH2.1 and NbEH2.2, and both can be found in the EH2 clade.

It appears that many plants usually have both $\mathrm{EH} 1$ and $\mathrm{EH} 2$ type sequences. In addition to $N$. benthamiana, there are both EH1 and EH2 type sequences in N. tabacum, C. annuum, L. esculentum and S. tuberosum (Fig. 1). However, this is not limited to plants belonging to the Solanaceae. A partial search of EH sequences from the Phytome database (http://www.phytome.org/, accessed 10 July 2007) and the DFCI Gene Indices (http://compbio.dfci. harvard.edu/) showed a wide range of plants that had both EH1 and EH2 type sequences. This included a gymnosperm, Pinus taeda L., and the dicotyledonous angiosperms, Aquilegia formosa Fisch. ex DC., Aquilegia pubescens Coville, Brassica napus L., Citrus clementina Hort. ex Tan., Gossypium hirsutum L., Liriodendron tulipifera L., Mesembryanthemum crystallinum L., Phaseolus vulgaris L., and Vitis vinifera L., which each belong to a different plant family. Also, both EH1 and EH2 type sequences were found in the monocotyledonous angiosperms, Allium cepa, Hordeum vulgare, Oryza sativa and Triticum aestivum. However, an exception was the Arabidopsis thaliana (L.) Heynh. genome, which contains $33 \mathrm{EH}$ genes that are all of the EH2 type (http://www.arabidopsis.org/, accessed 10 July 2007).

Expression of $\mathrm{NbEH} 1.1$ and $\mathrm{NbEH} 1.2$ in $\mathrm{N}$. benthamiana following infection by $\mathrm{C}$. destructivum, $\mathrm{C}$. orbiculare and P. syringae $p v$. tabaci

Expression of $\mathrm{NbEH1.1}$ did not change significantly until there was a significant increase at $72 \mathrm{HPI}$ with $C$. destructivum (Fig. 2A). This correlated with the appearance of small watersoaked spots at approximately $60 \mathrm{HPI}$. Expression of $\mathrm{NbEH1.2}$ was significantly greater than the water control only at $24 \mathrm{HPI}$ with C. destructivum, which is when the fungus is at the penetration and early biotrophic phase (Fig. $2 B$ ). No expression of $\mathrm{NbEH1.1}$ or $\mathrm{NbEH1.2}$ was detectable in the water control (Fig. 2).

A significant increase in $\mathrm{NbEH1.1}$ expression began at $24 \mathrm{HPI}$ with $C$. orbiculare continually increasing to a peak at 72 HPI (Fig. $3 A$ ). The peak in expression correlated with the appearance of small water-soaked spots at 64-72 HPI. In contrast, expression of $\mathrm{NbEH1.2}$ was never significantly different from the water control after infection with C. orbiculare (Fig. 3B). No expression of $N b E H 1.1$ or $N b E H 1.2$ was detectable in the water control (Fig. 3).

Expression of $\mathrm{NbEH1.1}$ first significantly increased at $48 \mathrm{HPI}$ with $P$. syringae pv. tabaci and then continued to increase at progressively faster rates (Fig. $4 A$ ). In contrast, expression of 


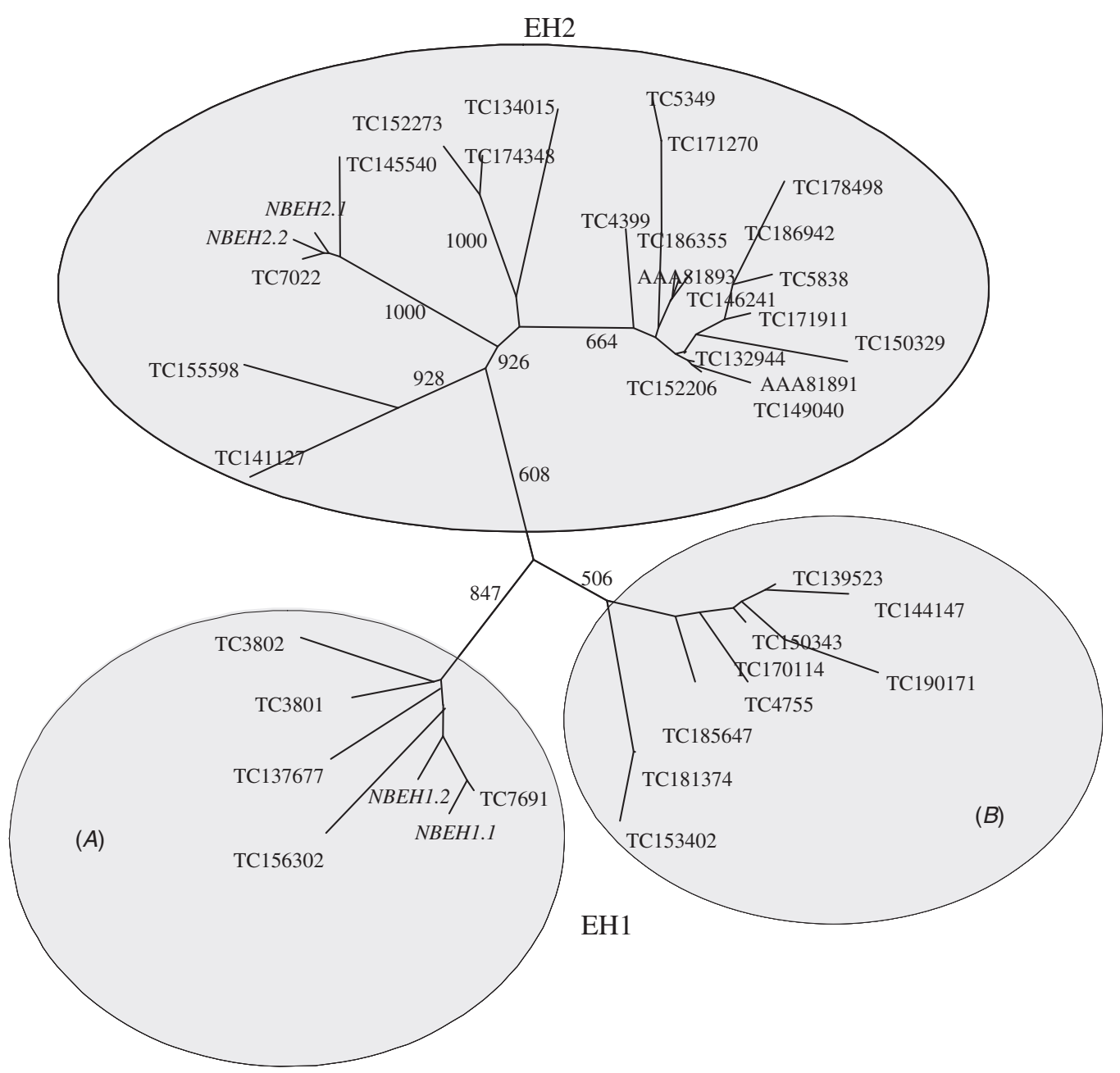

Fig. 1. Comparison of $\alpha / \beta$ hydrolase fold family epoxide hydrolase (EH) sequences from plants in the Solanaceae. Amino acid sequences were aligned using CLUSTALX, and bootstrap analysis conducted using the NJ-bootstrap procedure of CLUSTALX. The values near major branches represent that number of times out of 1000 that the branch was supported by bootstrap analysis, and only branches with over $50 \%$ support are marked. The two EH1 subclusters and the EH2 cluster are marked in grey.

NbEH1.2 first significantly increased at 24 HPI peaking at 48 HPI (Fig. 4B). For P. syringae pv. tabaci, the significant increases in both NbEH1.1 and NbEH1.2 expression began before the appearance of water-soaking that developed at approximately $72 \mathrm{HPI}$. No expression of $\mathrm{NbEH1.1}$ or $\mathrm{NbEH1.2}$ was detectable in the buffer infiltration control (Fig. 4).

Expression of NbEH1.1 in N. benthamiana (Pto) inoculated with $P$. syringae pv. tabaci (avrPto) increased after infiltration with a peak at 15 HPI (Fig. 5A). The decline from the peak expression corresponded with visible HR necrosis at 16-18 HPI. Expression of NbEH1.2 did not show such a peak in expression but only fluctuated somewhat after an initial significant increase at $3 \mathrm{HPI}$ (Fig. 5B). No expression of $\mathrm{NbEH1.1}$ or $\mathrm{NbEH1.2}$ was detectable in the buffer infiltration control (Fig. 5).

To confirm the identity of the EH RT-PCR product, bands amplified from cDNA at $72 \mathrm{HPI}$ with $P$. syringae pv. tabaci using the primers for relative RT-PCR of $\mathrm{NbEH1.1}$ or $\mathrm{NbEH1.2}$ were directly sequenced. The sequences had $100 \%$ nt identity with the corresponding regions of $\mathrm{NbEH1.1}$ and $\mathrm{NbEH1.2.}$

Silencing $\mathrm{NbEH} 1.1$ in $\mathrm{N}$. benthamiana and the response to inoculation with $\mathrm{C}$. destructivum or C. orbiculare

TRV-mediated VIGS of NbEH1.1 in N. benthamiana decreased NbEH1.1 expression to non-detectable levels, whereas considerable expression was detected in the buffer and TRVGFP controls at 72 HPI with $C$. destructivum (Fig. 6; Table 2). Expression of NbEH1.2 was also tested to see if it was affected by silencing $N b E H 1.1$, but there was no detectable expression in the buffer and TRV vector controls or in $\mathrm{NbEH1.1-}$ silenced plants. However, $\mathrm{NbEH2.1}$ expression was detected and was not affected by silencing NbEH1.1 indicating the relative specificity of silencing (Table 2).

Silencing of $\mathrm{NbEH1.1}$ expression was also observed at $72 \mathrm{HPI}$ with $C$. orbiculare compared with the buffer and TRV-GFP controls (Fig. 6; Table 2). No detectable NbEH1.2 expression 


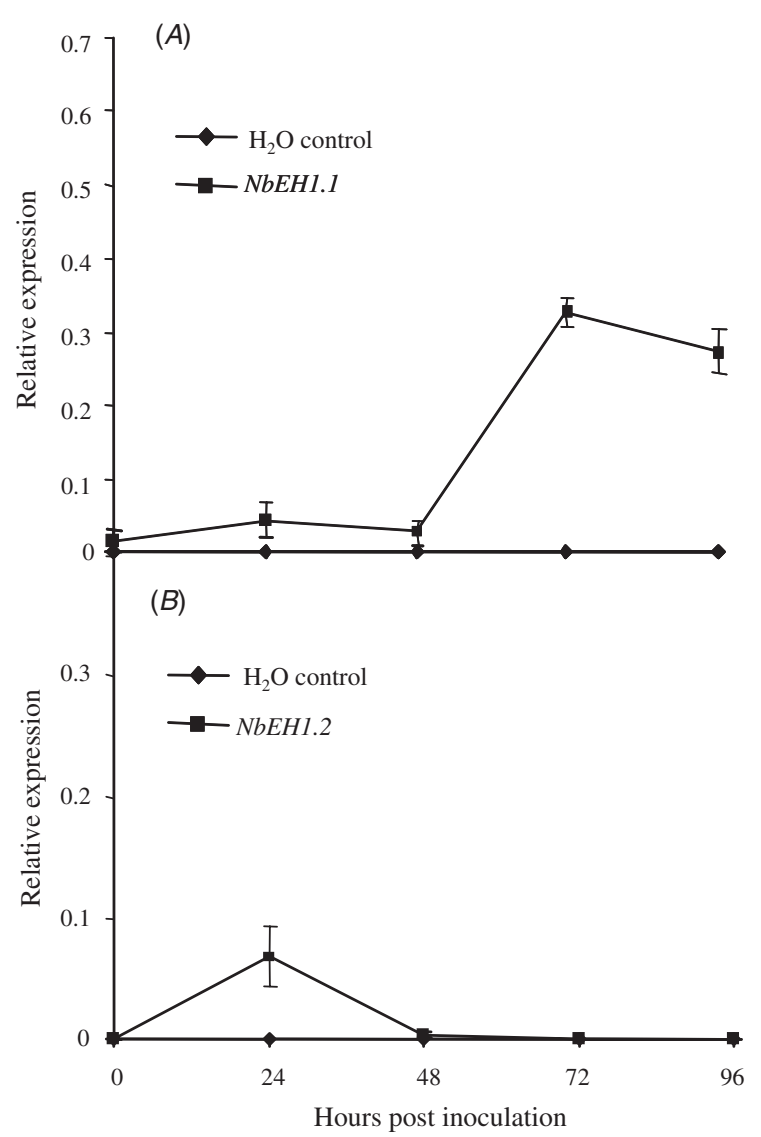

Fig. 2. Relative reverse transcription (RT)-PCR of (A) NbEH1.1 and (B) NbEH1.2 expression in Nicotiana benthamiana leaves inoculated with

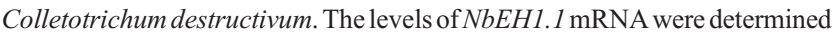
relative to the level of expression of $N b E F-1 \alpha$. Means are shown with standard error bars calculated from three replications.

was found in the buffer control, TRV vector control or NbEH1.1silenced plants inoculated with $\mathrm{C}$. orbiculare, but $\mathrm{NbEH2.1}$ expression was detected and was not affected by silencing of NbEH1.1.

NbEH1.1-silenced plants had significantly fewer watersoaked lesions on leaves at $64 \mathrm{HPI}$ with $C$. destructivum compared with the controls, but by $72 \mathrm{HPI}$, lesion number was not significantly different between $\mathrm{NbEH1.1-silenced} \mathrm{and} \mathrm{non-}$ silenced plants (Table 3). This indicates that the development of necrosis was delayed for a significant number of infection sites. Although large numbers of water-soaked lesions became visible several hours later in $\mathrm{NbEH1}$.1-silenced plants compared with the controls, there was no difference in the appearance of the lesions with the different treatments. In contrast, there was no significant difference in the lesion number on leaves of NbEH1.1-silenced plants compared with the controls at either 64 or 72 HPI for C. orbiculare (Table 3).

Silencing $\mathrm{NbEH} 1.1$ in $\mathrm{N}$. benthamiana and the response to inoculation with $\mathrm{P}$. syringae $p v$. tabaci or P. syringae pv. tabaci (avrPto)

TRV-mediated VIGS of NbEH1.1 resulted in a significant decrease in $\mathrm{NbEH1.1}$ expression compared with the buffer and

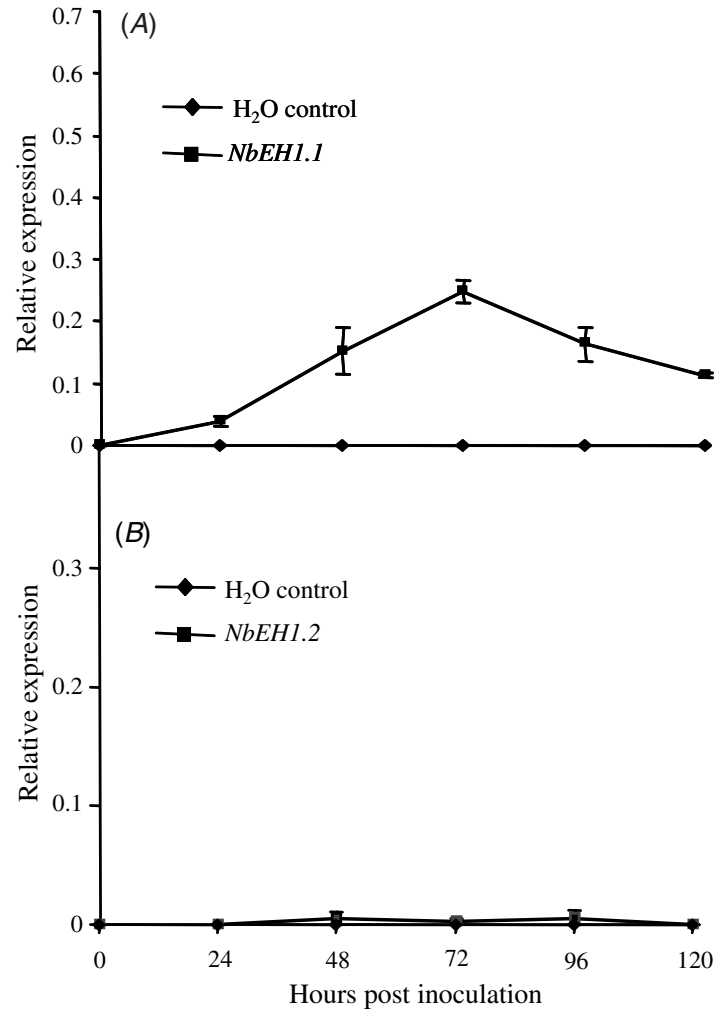

Fig. 3. Relative reverse transcription (RT)-PCR of $(A) N b E H 1.1$ and (B) NbEH1.2 expression in Nicotiana benthamiana leaves inoculated with Colletotrichum orbiculare. The levels of NbEH1.1 and NbEH1.2 messenger RNA were determined relative to the level of expression of $N b E F-1 \alpha$. Means are shown with standard error bars calculated from three replications.

TRV-GFP controls at 72 HPI during the susceptible response of wild type $N$. benthamiana to $P$. syringae pv. tabaci (Fig. 6; Table 4). TRV-mediated VIGS of NbEH1.1 also resulted in significantly less $\mathrm{NbEH1.1}$ expression in $\mathrm{NbEH1.1}$-silenced $N$. benthamiana (Pto) plants compared with the controls at 15 HPI during the HR resistance to P. syringae pv. tabaci (avrPto) (Fig. 6; Table 4). Silencing appeared to be relatively specific for these susceptible and resistant responses as there was never a significant difference in the expression of $\mathrm{NbEH1.2}$ in the NbEH1.1-silenced plants compared with the controls (Fig. 6; Table 4).

After inoculation with $P$. syringae pv. tabaci, bacterial populations at $72 \mathrm{HPI}$ were significantly lower in $\mathrm{NbEH1.1-}$ silenced wild type $N$. benthamiana compared with the $\mathrm{MgCl}_{2}$ control or the TRV-GFP control (Table 5). Despite the lower bacterial population, the timing and appearance of necrosis in the susceptible response did not differ between silenced and nonsilenced plants. In the resistant response, silencing NbEH1.1 resulted in significantly higher population levels of $P$. syringae pv. tabaci (avrPto) at $12 \mathrm{HPI}$ in the NbEH1.1-silenced $N$. benthamiana (Pto) compared with the $\mathrm{MgCl}_{2}$ control or the TRV-GFP control (Table 5). There were no differences between silenced and non-silenced plants in the timing and appearance of HR necrosis. 


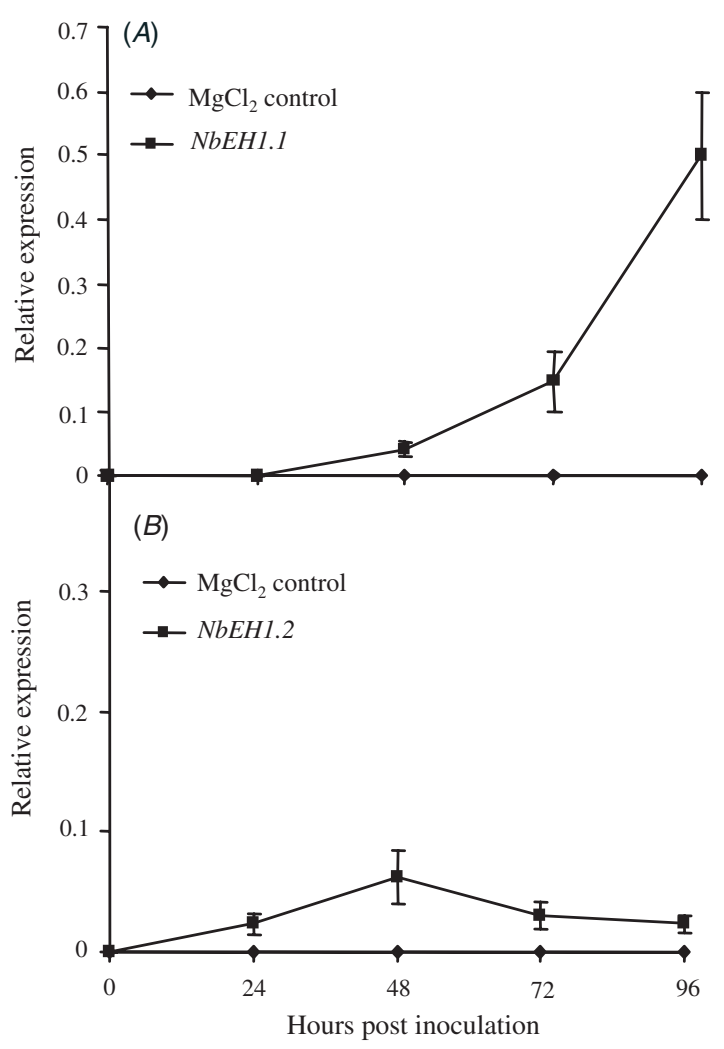

Fig. 4. Relative reverse transcription (RT)-PCR of $(A) N b E H 1.1$ and $(B)$ NbEH1.2 expression in Nicotiana benthamiana leaves inoculated with Psuedomonas syringae pv. tabaci. The messenger RNA levels of $N b E H 1.1$ and NbEH1.2 were determined relative to the level of expression of $N b E F-1 \alpha$. Means are shown with standard error bars calculated from three replications.

\section{Discussion}

An EH gene, NbEH1.1, was identified in N. benthamiana that has relatively high sequence identity to $N t E H-1$ from $N$. tabacum. In the DFCI $N$. benthamiana Gene Index, three other $N$. benthamiana EH genes were identified with much less similarity to $N t E H-1$. However, it is likely that there are additional EH genes in $N$. benthamiana, since other solanaceous plants, such as L. esculentum and S. tuberosum, have 10 and 18 tentative consensus sequences for $\mathrm{EH}$, respectively, in the DFCI Gene Indices.

At 24 HPI with $C$. destructivum, only expression of $\mathrm{NbEH1.2}$ significantly increased, followed by a decline. At that time, the fungus was penetrating the cuticle with an appressorium, although some infections have begun producing a vesicle in epidermal cells beginning the biotrophic phase (Shen et al. 2001a). This suggests that, unlike NbEH1.1, NbEH1.2 expression may be related to penetration of the cuticle and/or early biotrophy. Components of the cuticle include cutin monomer epoxides, such as 9,10-epoxy-18-hydroxystearic acid, that are produced by EH (Kolattukudy 1981). In leaves of Citrus jambhiri Lush., expression of an EH gene, RlemEH, was induced during appressorial penetration of the cuticle by the virulent fungus, Alternaria alternata, and RlemEH might help in reinforcing and repairing cuticle damage caused by penetration

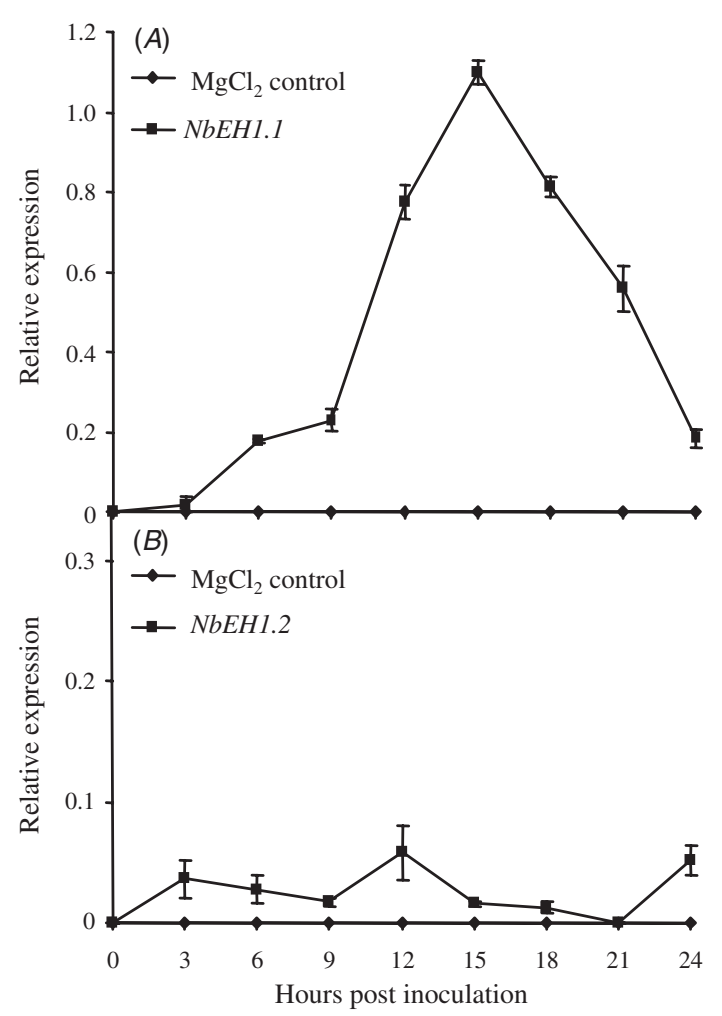

Fig. 5. Relative reverse transcription (RT)-PCR of $(A) \mathrm{NbEH1.1}$ and $(B)$ NbEH1.2 expression in Nicotiana benthamiana (Pto) leaves inoculated with Pseudomonas. syringae pv tabaci (avrPto). The levels of NbEHI.1 and NbEH1.2 messenger RNA levels were determined relative to the level of expression of $N b E F-1 \alpha$. Means are shown with standard error bars calculated from three replications.

Table 2. Relative reverse transcription (RT)-PCR analysis of silencing of $\mathrm{NbEH1.1,} \mathrm{NbEH1.2}$ and $\mathrm{NbEH} 2.2$ using $\mathrm{MgCl}_{2}$ control, tobacco rattle virus (TRV) vector control (TRV-green fluorescent protein gene, GFP) and NbEH1.1-silenced Nicotiana benthamiana at 72 HPI with Colletotrichum destructivum or Colletotrichum orbiculare

\begin{tabular}{|c|c|c|c|c|}
\hline \multirow[t]{2}{*}{ Pathogen } & \multirow[t]{2}{*}{ Treatment $^{\mathrm{A}}$} & \multicolumn{3}{|c|}{ Relative gene expression ${ }^{\mathrm{B}}$} \\
\hline & & NbEH1.1 & $\mathrm{NbEH1.2}$ & $\mathrm{NbEH2.2}$ \\
\hline C. destructivum & $\mathrm{MgCl}_{2}$ control & $0.37 \mathrm{a}$ & $0.00 \mathrm{a}$ & $0.28 \mathrm{a}$ \\
\hline C. destructivum & TRV-GFP control & $0.16 \mathrm{~b}$ & $0.00 \mathrm{a}$ & $0.29 \mathrm{a}$ \\
\hline C. destructivum & TRV-NbEH1.1 & $0.00 \mathrm{c}$ & $0.00 \mathrm{a}$ & $0.30 \mathrm{a}$ \\
\hline C. orbiculare & $\mathrm{MgCl}_{2}$ control & $1.64 \mathrm{a}$ & $0.00 \mathrm{a}$ & $0.39 \mathrm{a}$ \\
\hline C. orbiculare & TRV-GFP control & $0.96 \mathrm{~b}$ & $0.00 \mathrm{a}$ & $0.34 \mathrm{a}$ \\
\hline C. orbiculare & TRV-NbEH1.1 & $0.04 \mathrm{c}$ & $0.00 \mathrm{a}$ & $0.38 \mathrm{a}$ \\
\hline
\end{tabular}

${ }^{\mathrm{A}} \mathrm{NbEH1}$.1-silenced and TRV vector control $N$. benthamiana plants were inoculated with Agrobacterium tumefaciens containing TRV in a tumor inducing (Ti) plasmid with a GFP insert or a fragment of $\mathrm{NbEH1.1} . \mathrm{MgCl}_{2}$ control plants were inoculated with buffer only.

${ }^{\mathrm{B}}$ Expression of $\mathrm{NbEH1.1,} \mathrm{NbEH1.2}$ and $\mathrm{NbEH} 2.1$ in $\mathrm{MgCl}_{2}$ control in $\mathrm{MgCl}_{2}$ control, TRV vector control or NbEH1.1-silenced $N$. benthamiana was determined by relative RT-PCR following infection with $C$. destructivum or $C$. orbiculare. Each value represents the mean relative expression from at least three experiments. Means for each pathogen in the same column followed by the same letter are not significantly different according to the protected LSD test at $P=0.05$. 
TRV-

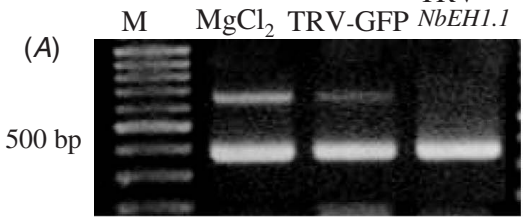

NbEH1.1 NbEF1a

TRV-

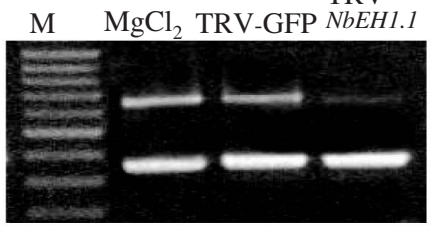

NbEH1.1

$500 \mathrm{bp}$

NbEF1a

TRV-

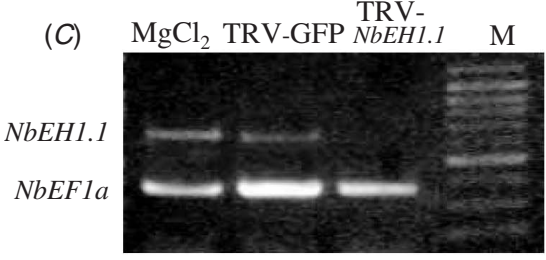

$500 \mathrm{bp}$

TRV-

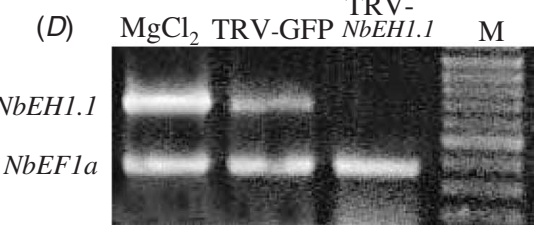

$500 \mathrm{bp}$

Fig. 6. Gel pictures of relative reverse transcription (RT)-PCR of NbEH1.1 in NbEH1.1-silenced Nicotiana benthamiana and $\mathrm{MgCl}_{2}$ and tobacco rattle virus (TRV)-green fluorescent protein gene (GFP) controls. $\mathrm{NbEH1.1}$ was coamplified with $N b E F-1 \alpha$ using coding DNA from the interaction at $72 \mathrm{~h}$ post inoculation (HPI) with (A) Colletotrichum destructivum, $(B)$ Colletotrichum orbiculare or $(C)$ Pseudomonas syringae pv. tabaci or $(D) 15$ HPI with P. syringae pv. tabaci (avrPto). Lanes are: $\mathrm{MgCl}_{2}$, which is the buffer only infiltration control, TRV-GFP, which is the virus vector control with Agrobacterium tumefaciens containing pTRV2 with a green fluorescent protein gene and TRV-NbEH1.1 which is the A.tumefaciens containing pTRV2 with a fragment of NbEH1.1, and M, which is the $100 \mathrm{bp}$ ladder.

(Gomi et al. 2003). Colletotrichum destructivum penetration also involves appressoria, and thus NbEH1.2 may also be involved in reinforcing the cuticle.

Expression of $\mathrm{NbEH1.1}$ remained low during penetration and the biotrophic phase of $C$. destructivum when multi-lobed vesicles were growing and invaginating the initially infected leaf epidermal cell (Shen et al. 2001a). However, at approximately $60 \mathrm{HPI}$, secondary hyphae developed from the ends of the vesicles to penetrate adjacent cells and produce water soaked spots, correlating with the timing of increased $\mathrm{NbEH1.1}$ expression. It appears that $\mathrm{NbEH1.1}$ expression is induced by changes in host cells due to fungal necrotrophy, but not penetration or even extensive biotrophy, making it more likely that it is associated with responses like catabolism of epoxides to non-toxic forms or production of antimicrobial compounds, rather than cuticle reinforcement (Ohta et al. 1991; Murray et al. 1993; Gomi et al. 2003).

In contrast to the $C$. destructivum infection, NbEH1.1 expression increased at a relatively constant level when
Table 3. Lesion number in $\mathrm{MgCl}_{2}$ control, tobacco rattle virus (TRV) vector control, NbEH1.1-silenced Nicotiana benthamiana at 64 and $72 \mathrm{~h}$ post inoculation (HPI) with Colletotrichum destructivum or 72 and 96 HPI with Colletotrichum orbiculare

\begin{tabular}{lcccc}
\hline Treatment $^{\mathrm{A}}$ & \multicolumn{2}{c}{ C. destructivum } & \multicolumn{2}{c}{ C. orbiculare } \\
& $\begin{array}{c}\text { Lesions } / \mathrm{cm}^{2} \\
\text { at } 64 \mathrm{HPI}^{\mathrm{B}}\end{array}$ & $\begin{array}{c}\text { Lesions } / \mathrm{cm}^{2} \\
\text { at } 72 \mathrm{HPI}^{\mathrm{B}}\end{array}$ & $\begin{array}{c}\text { Lesions } / \mathrm{cm}^{2} \\
\text { at } 72 \mathrm{HPI}^{\mathrm{B}}\end{array}$ & $\begin{array}{c}\text { Lesions } / \mathrm{cm}^{2} \\
\text { at } 96 \mathrm{HPI}^{\mathrm{B}}\end{array}$ \\
\hline $\mathrm{MgCl}_{2}$ control & $0.96 \mathrm{a}$ & $1.25 \mathrm{a}$ & $0.23 \mathrm{a}$ & $0.31 \mathrm{a}$ \\
TRV-GFP control & $0.80 \mathrm{a}$ & $1.01 \mathrm{a}$ & $0.18 \mathrm{a}$ & $0.38 \mathrm{a}$ \\
TRV-NbEH1.1 & $0.32 \mathrm{~b}$ & $0.97 \mathrm{a}$ & $0.19 \mathrm{a}$ & $0.35 \mathrm{a}$ \\
\hline
\end{tabular}

$\overline{{ }^{\mathrm{A}} \mathrm{NbEH1} \text {. } 1 \text {-silenced and TRV vector control } N \text {. benthamiana plants were }}$ inoculated with Agrobacterium tumefaciens containing TRV in a tumor inducing (Ti) plasmid with a green fluorescent protein gene (GFP) insert or a fragment of $\mathrm{NbEH1.1}$. $\mathrm{MgCl}_{2}$ control plants were inoculated with buffer only.

${ }^{\mathrm{B}}$ Lesions $/ \mathrm{cm}^{2}$ were means from two experiments with a total of 16 replications collected from 5 -week-old plants. Means in the same column followed by the same letter are not significantly different according to the protected LSD test at $P=0.05$.

Table 4. Relative reverse transcription (RT)-PCR analysis of silencing of $\mathrm{NbEH1}$.1 and $\mathrm{NbEH1.2}$ in $\mathrm{MgCl}_{2}$ control, tobacco rattle virus (TRV) vector control and $\mathrm{NbEH1}$.1-silenced Nicotiana benthamiana at $72 \mathrm{~h}$ post inoculation (HPI) with Pseudomonas syringae pv. tabaci or at 15 HPI with P. syringae pv. tabaci (avrPto)

\begin{tabular}{lcccc}
\hline Treatment $^{\mathrm{A}}$ & \multicolumn{3}{c}{ Relative gene expression } \\
& $\begin{array}{c}\text { P. syringae pv. } \\
\text { tabaci }\end{array}$ & $\begin{array}{c}\text { P. syringae pv. tabaci } \\
\text { (avrPto) }\end{array}$ \\
& NbEH1.1 & NbEH1.2 & NbEH1.1 & NbEH1.2 \\
\hline $\mathrm{MgCl}_{2}$ control & $0.49 \mathrm{a}$ & $0.57 \mathrm{a}$ & $0.74 \mathrm{a}$ & $0.68 \mathrm{a}$ \\
$\mathrm{TRV}-$ GFP control & $0.21 \mathrm{~b}$ & $0.56 \mathrm{a}$ & $0.38 \mathrm{~b}$ & $0.65 \mathrm{a}$ \\
$\mathrm{TRV}-N b E H 1.1$ & $0.00 \mathrm{c}$ & $0.58 \mathrm{a}$ & $0.00 \mathrm{c}$ & $0.63 \mathrm{a}$
\end{tabular}

$\overline{\mathrm{A}} \mathrm{NbEH1.1- \text {-silencedandTRVvectorcontrol } N \text { . benthamiana plants were }}$ inoculated with $A$. tumefaciens containing TRV in a tumor inducing (Ti) plasmid with a green fluorescent protein gene (GFP) insert or a fragment of NbEH1.1. $\mathrm{MgCl}_{2}$ control plants were inoculated with buffer only.

${ }^{\mathrm{B}}$ Expression of $\mathrm{NbEH1.1}, \mathrm{NbEH1.2}$ and $\mathrm{NbEH} 2.1$ in $\mathrm{MgCl}_{2}$ control, TRV vector control or NbEH1.1-silenced N. benthamiana or N. benthamiana (Pto) was determined by relative RT-PCR following infection with $P$. syringae pv. tabaci or pv. tabaci (avrPto), respectively. Each value represents the mean relative expression from at least three experiments. Means within the same column followed by the same letter are not significantly different according to the protected LSD test at $P=0.05$.

C. orbiculare grew biotrophically, producing large primary hyphae that penetrate and invaginate the cytoplasm of multiple host cells (Shen et al. 2001b). After approximately 72 HPI, necrotrophy began with thin secondary hyphae growing through host cells producing water-soaked spots and visible lesions. Penetration of multiple host cells occurs during the biotrophic phase of $C$. orbiculare but not for $C$. destructivum (Shen et al. 2001a, 2001b). Therefore, one explanation for the difference in $\mathrm{NbEH1.1}$ expression is that as C. orbiculare spreads from cell to cell by large primary hyphae, it degrades some of the cell wall, which could generate plant cell wall-based signal molecules that can affect host gene expression (Vidhyasekaran 2008). 
Table 5. Bacterial populations in $\mathbf{M g C l}_{2}$ control, tobacco rattle virus (TRV) vector control, NbEH1.1-silenced Nicotiana benthamiana at $72 \mathrm{~h}$ post inoculation (HPI) with Psuedomonas syringae pv. tabaci or $N$. benthamiana (Pto) at $12 \mathrm{HPI}$ with $P$. syringae pv. tabaci (avrPto)

\begin{tabular}{lcc}
\hline Treatment $^{\mathrm{A}}$ & $\begin{array}{c}\text { P. syringae pv. tabaci } \\
\text { CFU/cm }\end{array}$ & $\begin{array}{c}\text { P. syringae } \mathrm{pv} \text {. tabaci (avrPto) } \\
\text { CFU } / \mathrm{cm}^{2 \mathrm{~B}}\end{array}$ \\
\hline $\mathrm{MgCl}_{2}$ control & $1.71 \times 10^{7} \mathrm{a}$ & $5.50 \times 10^{6} \mathrm{a}$ \\
TRV-GFP control & $1.44 \times 10^{7} \mathrm{a}$ & $2.53 \times 10^{6} \mathrm{a}$ \\
TRV-NbEH1.1 & $9.55 \times 10^{6} \mathrm{~b}$ & $3.33 \times 10^{7} \mathrm{~b}$ \\
\hline
\end{tabular}

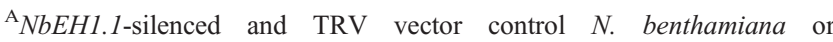
$N$. benthamiana (Pto) plants were inoculated with Agrobacterium tumefaciens containing TRV in a tumor inducing (Ti) plasmid with a GFP insert or a fragment of NbEH1.1. $\mathrm{MgCl}_{2}$ control plants were inoculated with buffer only.

${ }^{\mathrm{B}}$ Colony forming units $(\mathrm{CFU}) / \mathrm{cm}^{2}$ were means from two experiments with a total of 16 replications collected from 5-week-old plants. Means in the same column followed by the same letter are not significantly different according to the protected LSD test at $P=0.05$.

Unlike the interaction with $C$. destructivum, expression of $N b E H 1.2$ always remained low with $C$. orbiculare. The reason for the difference in $\mathrm{NbEH1.2}$ expression during penetration between the interactions with $C$. destructivum and $C$. orbiculare is unclear since penetration by both fungi occurs with appressoria and penetration pegs.

Pseudomonas syringae has a Type III Secretion System (TTSS) to secrete effectors directly into plant cells that are essential for biotrophic bacterial multiplication in the apoplast of plant tissue (Mudgett 2005). A major role for TTSS effectors is to perturb host cell metabolism to create more favourable conditions for the pathogen, typically by suppressing defence processes (Da Cunha et al. 2007). However, increased NbEH1.1 expression was first observed during biotrophic growth of $P$. syringae pv. tabaci in the apoplast, indicating that the plant had detected the pathogen. At approximately $72 \mathrm{HPI}$, the bacteria became necrotrophic degrading host cell walls and spreading into the host cytoplasm from the apoplast producing symptoms (Lucas 1965). This marked the start of an accelerated increase in $\mathrm{NbEH1.1}$ expression. In contrast, expression of $\mathrm{NbEH1.2}$ was induced earlier than NbEH1.1 and peaked during biotrophic phase. It is therefore possible that $\mathrm{NbEH1.1}$ expression could be associated with stress or defence responses later in the interaction as bacterial populations become larger, while $\mathrm{NbEH1.2}$ expression could be associated with cutin synthesis earlier in the interaction. Cutin would not be involved in the same way for infections by $P$. syringae compared with $C$. destructivum because the bacterium does not directly penetrate the cuticle. However, cells in the substomatal cavity, which is invaded once bacteria enter thorough stomata, are covered with a cuticle membrane, and cutin-related fatty acids can repress TTSS gene expression (Xiao et al. 2004).

The interaction of $N$. benthamiana (Pto) with P. syringae pv. tabaci (avrPto) (Rommens et al. 1995) results in an HR when the TTSS effector encoded by avrPto enters the cell and interacts with its target that is guarded by Pto (Ronald 1992). During the HR, expression of $\mathrm{NbEH1.1}$ was induced with a peak before cell death that was much higher than in any of the compatible interactions examined in this study. In contrast, $\mathrm{NbEH1.2}$ expression does not appear to have a close relationship to the HR as NbEH1.1 expression showed only a slight increase during the HR.

$N t E H-1$ expression, like NbEH1.1 expression, was also upregulated before the appearance of necrosis in the HR to P. syringae pv. syringae and TMV (Malamy et al. 1992; Guo et al. 1998; Szatmari et al. 2006). One difference, however, is that $N t E H-1$ expression was not induced in the susceptible response to TMV (Guo et al. 1998), but NbEH1.1 expression was induced during all the susceptible responses in the current study. This may be related to the biotrophic nature of TMV verses the hemibiotrophic pathogens examined in current study. Szatmari et al. (2006) also found that expression of $N t E H-1$ was induced in the susceptible response of $N$. tabacum to the hemibiotroph, $P$. syringae pv. tabaci, but to a lower level than in resistance responses.

Silencing of $\mathrm{NbEH1.1}$ was done by VIGS. An advantage of VIGS is that it allows plants to be grown to a mature state before silencing, thus avoiding unintended effects of silencing a gene on plant development. This is important for EHs as cutin biosynthesis is involved in plant development during germination, seed development and differentiation of meristematic tissues (Stapleton et al. 1994; Arahira et al. 2000; Edqvist and Farbos 2000).

TRV-mediated VIGS was very effective in lowering levels of NbEH1.1 expression. Since VIGS can affect genes with $80 \%$ or higher identity (Baulcombe 1999), genes closely related to NbEH1.1 may have been affected. The gene known to be most

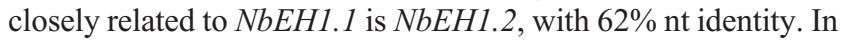
interactions where $\mathrm{NbEH1.2}$ expression could be detected, silencing $\mathrm{NbEH1.1}$ did not significantly affect its expression or that of a more distantly related gene, $N b E H 2.1$, showing that NbEH1.1 silencing was relatively specific.

For NbEH1.1-silenced plants infected with C. destructivum, fewer lesions were observed at $64 \mathrm{HPI}$, but by $8 \mathrm{~h}$ later, lesion numbers were similar to the controls. Thus, silencing $\mathrm{NbEH1.1}$ caused a delay in the appearance of the necrotrophic phase. Reduction of NbEH1.1 expression should result in less $\mathrm{EH}$ activity and thus higher levels of epoxides and epoxy fatty acids, such as epoxyhydroxy acids. Epoxyhydroxy acids, the main decomposition product of alkoxy radicals, have antifungal activity (Kato et al. 1983), and so silencing NbEH1.1 may have resulted in increased levels of inhibitory compounds that slowed fungal development thus delaying symptom appearance.

Although infection by $C$. destructivum was affected by silencing, there was no effect when NbEH1.1-silenced plants were inoculated with $C$. orbiculare. The earlier and more gradual increase in NbEH1.1 expression in plants inoculated with $C$. orbiculare compared with $C$. destructivum indicates that host epoxide production responds differently during infections by those two fungi, which could be related to why NbEH1.1 silencing did not affect the interactions in the same way.

For the infection by P. syringae pv. tabaci, silencing NbEH1.1 resulted in a significant inhibition of pathogen growth suggesting that, like with $C$. destructivum, reduced $\mathrm{EH}$ levels resulted in increased amounts of epoxides with antimicrobial activity. Epoxides with antibacterial activity could contribute to bacterial basal resistance. For example, a caryophyllene-4,5epoxide from Pilgerodendron uviferum (D. Don) Florin 
showed antibacterial activity against Staphylococcus aureus, Bacillus subtilis, E. coli, Pseudomonas aeruginosa and Streptococcus pyogenes (Solis et al. 2004). It was hypothesised that $N t E H-1$ was involved in basal resistance to $P$. syringae pv. tabaci and A. tumefaciens, as well as the response to the symbiont, Sinorhizobium meliloti (Szatmari et al. 2006). These compatible bacteria were believed to limit basal resistance, since induction of $N t E H-1$ was less than that caused by HR or non-HR inducing incompatible bacteria.

In contrast, silencing $\mathrm{NbEH1.1}$ resulted in higher bacterial populations during the HR in the gene-for-gene interaction of N. benthamiana (Pto) with P. syringae pv. tabaci (avrPto). As the $\mathrm{HR}$ is related to enzymatic lipid peroxidation and rapid formation of toxic epoxides (Gobel et al. 2003), Guo et al. (1998) speculated that NtEH-1 was highly induced to detoxify harmful metabolites produced during the oxidative burst, thus, helping to limit host cell death during the HR to TMV. However, silencing of $N b E H 1.1$, which is very similar to $N t E H-1$, did not result any significant change in HR associated cell death. Guo et al. (1998) also proposed that $N t E H-1$ may affect jasmonic acid synthesis and thus, defence signalling. This explanation would be compatible with our results, where silencing NbEH1.1 resulted in reduced HR resistance as indicated by greater bacterial growth.

Another explanation for silencing resulting in greater growth of $P$. syringae pv. tabaci (avrPto) during the $\mathrm{HR}$ is that silencing NbEH1.1 may have reduced the production of certain EHproduced oxylipin phytoalexins associated with the HR. An example of an oxylipin phytoalexin produced by EH is 13-Lhydroperoxy-9,11(Z,E)-octadecadienoic acid, which is formed in rice leaves during the HR to an incompatible race of Magnaporthe grisea (Herbert) Barr, and is able to inhibit conidial germination and germ tube growth (Ohta et al. 1991).

This is the first evidence that an EH gene can play a direct role in a plant-pathogen interaction. Each of the pathogens tested in this study induced a unique pattern of $N b E H 1.1$ expression, and silencing $\mathrm{NbEH1.1}$ resulted in no effect, inhibition or greater growth of the pathogen depending upon the interaction. Because of its potential roles in detoxification, signalling, as well as breakdown and synthesis of antimicrobial compounds, the role of EH in different plant-microbe interactions may be varied and complex.

\section{Acknowledgements}

Funding for this study was provided by the Natural Science and Engineering Research Council of Canada. Nicotiana benthamiana containing Pto was kindly provided by Dr R. Michelmore University of California, Davis, CA. Pseudomonas syringae pv. tabaci $11528 \mathrm{R}$ and P. syringae pv. tabaci 11528R containing avrPto were kindly provided by Dr Bridget Randall, Boyce Thompson Institute, Ithaca, NY.

\section{References}

Arahira M, Nong Udaka VHK, Fukazawa C (2000) Purification, molecular cloning and ethylene-inducible expression of a soluble-type epoxide hydrolase from soybean (Glycine max [L.] Merr.). European Journal of Biochemistry 267, 2649-2657. doi: 10.1046/j.14321327.2000.01276.x

Baulcombe D (1999) Fast forward genetics based on virus-induced gene silencing. Current Opinion in Plant Biology 2, 109-113. doi: 10.1016/ S1369-5266(99)80022-3
Baulcombe D (2004) RNA silencing in plants. Nature 431, 356-363. doi: 10.1038/nature02874

Beetham JK, Grant D, Arand M, Garbarino J, Kiyosue T, Pinot F (1995) Gene evolution of epoxide hydrolases and recommended nomenclature. DNA and Cell Biology 14, 61-71.

Blee E (1998) Phyto-oxylipins and plant defense reactions. Progress in Lipid Research 37, 33-72. doi: 10.1016/S0163-7827(98)00004-6

Blee E (2002) Impact of phyto-oxylipins in plant defense. Trends in Plant Science 7, 315-322. doi: 10.1016/S1360-1385(02)02290-2

Chen N, Hsiang T, Goodwin PH (2003) Use of green fluorescent protein to quantify the growth of Colletotrichum during infection of tobacco. Journal of Microbiological Methods 53, 113-122. doi: 10.1016/ S0167-7012(02)00234-8

Chenna R, Sugawara H, Koike T, Lopez R, Gibson TJ, Higgins DG, Thompson JD (2003) Multiple sequence alignment with the Clustal series of programs. Nucleic Acids Research 31, 3497-3500. doi: $10.1093 / \mathrm{nar} / \mathrm{gkg} 500$

Da Cunha L, Sreerekha MV, Mackey D (2007) Defense suppression by virulence effectors of bacterial phytopathogens. Current Opinion in Plant Biology 10, 349-357. doi: 10.1016/j.pbi.2007.04.018

Dean JD, Goodwin PH, Hsiang T (2002) Comparison of relative RT-PCR and northern blot analyses to measure expression of $\beta$-1,3-glucanase in Nicotiana benthamiana infected with Colletotrichum destructivum. Plant Molecular Biology Reporter 20, 347-356. doi: 10.1007/ BF02772122

Dinesh-Kumar SP, Anandalakshmi R, Marathe R, Schiff M, Liu Y (2003) Virus-induced gene silencing. In 'Methods in molecular biology plant functional genomics'. (Ed. E Grotewold) pp. 286-293. (Humana Press: Totowa, $\mathrm{NJ}$ )

Edqvist J, Farbos I (2000) Characterization of an Euphorbia lagascae epoxide hydrolase gene which is induced early during germination. Biochemical Society Transactions 28, 855-857. doi: 10.1042/BST0280855

Gobel C, Feussner I, Rosahl S (2003) Lipid peroxidation during the hypersensitive response in potato in the absence of 9-lipoxygenases. Journal of Biological Chemistry 278, 52834-52840. doi: 10.1074/jbc. M310833200

Gomi K, Yamamoto H, Akimitsu K (2003) Epoxide hydrolase: a mRNA induced by the fungal pathogen Alternaria alternata on rough lemon (Citrus jambhiri Lush). Plant Molecular Biology 53, 189-199. doi: 10.1023/B:PLAN.0000009287.95682.24

Guo A, Durner J, Klessig DF (1998) Characterization of a tobacco epoxide hydrolase gene induced during the resistance response to TMV. The Plant Journal 15, 647-656. doi: 10.1046/j.1365-313x.1998.00241.x

Hamberg M, Hamberg G (1996) Peroxygenase-catalyzed fatty acid epoxidation in cereal seeds: Sequential oxidation of linoleic acid into 9 (S),12(S),13(S)-trihydroxy-10(E)-octadecenoic acid. Plant Physiology 110, 807-815.

Hammerschmidt R (1999) Phytoalexins: What have we learned after 60 years? Annual Review of Phytopathology 37, 285-306. doi: 10.1146/annurev. phyto.37.1.285

Hao L, Hsiang T, Goodwin PH (2006) Role of two cysteine proteinases in the susceptible response of Nicotiana benthamiana to Colletotrichum destructivum and hypersensitive response to Pseudomonas syringae pv. tomato. Plant Science 170, 1001-1009. doi: 10.1016/j.plantsci. 2006.01.011

Kato T, Yamaguchi Y, Uyehara T, Yokkoyama T, Namai T, Yamanaka S (1983) Self-defensive substances in rice plant against rice plant disease. Tetrahedron Letters 24, 4715-4718. doi: 10.1016/S0040-4039(00) 86236-X

King EO, Ward MK, Raney DE (1954) Two simple media for the demonstration of pyocyanin and fluorescin. Journal of Laboratory and Clinical Medicine 44, 301-307.

Kolattukudy PE (1981) Structure, biosynthesis, and biodegradation of cutin and suberin. Annual Review of Plant Physiology 32, 539-567. doi: 10.1146/annurev.pp.32.060181.002543 
Liu Y, Schiff M, Marathe R, Dinesh-Kumar SP (2002) Tobacco Rarl, EDS1 and NPRI/NIM1 like genes are required for $\mathrm{N}$-mediated resistance to tobacco mosaic virus. The Plant Journal 30, 415-429. doi: 10.1046/ j.1365-313X.2002.01297.x

Lucas GB (1965) 'Diseases of tobacco.' (Scarecrow Press: New York, NY).

Malamy J, Hennig J, Klessig DJ (1992) Temperature-dependent induction of salicylic acid and its conjugate during the resistance response to tobacco mosaic virus infection. The Plant Cell 4, 359-366. doi: $10.2307 / 3869546$

Manandhar J, Hartman G, Sinclair J (1986) Colletotrichum destructivum, the anamorph of Glomerella glycines. Phytopathology 76, 282-285.

Matsuoka K, Demura T, Galis I, Horiguchi T, Sasaki M, Tashiro G, Fukuda H (2004) A comprehensive gene expression analysis toward the understanding of growth and differentiation of tobacco BY-2 cells. Plant \& Cell Physiology 45, 1280-1289. doi: 10.1093/pcp/pch155

Mudgett MB (2005) New insights to the function of phytopathogenic bacterial type III effectors in plants. Annual Review of Plant Biology 56, 509-531. doi: 10.1146/annurev.arplant.56.032604.144218

Murray GI, Paterson PJ, Weaver RJ, Ewen SW, Melvin WT, Burke MD (1993) The expression of cytochrome P-450, epoxide hydrolase, and glutathione S-transferase in hepatocellular carcinoma. Cancer 71, 36-43. doi: 10.1002/1097-0142(19930101)71:1<36::AID-CNCR2820710107 $>3.0 . \mathrm{CO} ; 2-\mathrm{J}$

Newman JW, Morisseau C, Hammock BD (2005) Epoxide hydrolases: their roles and interactions with lipid metabolism. Progress in Lipid Research 44, 1-51. doi: 10.1016/j.plipres.2004.10.001

Nicot N, Hausman JF, Hoffmann L, Evers D (2005) Housekeeping gene selection for real-time RT-PCR normalization in potato during biotic and abiotic stress. Journal of Experimental Botany 56, 2907-2914. doi: $10.1093 / \mathrm{jxb} / \mathrm{eri} 285$

Ohta H, Shida K, Peng YL, Furusawa I, Shishiyama J, Aibara S, Morita Y (1991) A lipoxygenase pathway is activated in rice after infection with the rice blast fungus Magnaporthe grisea. Plant Physiology 97, 94-98.

Prost I, Dhondt S, Rothe G, Vicente J, Rodriguez MJ et al. (2005) Evaluation of the antimicrobial activities of plant oxylipins supports their involvement in defense against pathogens. Plant Physiology 139, 1902-1913. doi: 10.1104/pp.105.066274

Robertson D (2004) VIGS vectors for gene silencing: many targets, many tools. Annual Review of Plant Biology 55, 495-519. doi: 10.1146/ annurev.arplant.55.031903.141803

Rommens CMT, Salmeron JM, Oldroyd GED, Staskawicz BJ (1995) Intergeneric transfer and functional expression of the tomato disease resistance gene Pto. The Plant Cell 7, 1537-1544. doi: 10.2307/3870017
Ronald PC (1992) The cloned avirulence gene avrPto induces disease resistance in tomato cultivars containing the Pto resistance gene. Journal of Bacteriology 174, 1604-1611.

Shen S, Goodwin PH, Hsiang T (2001a) Hemibiotrophic infection and identity of the fungus, Colletotrichum destructivum, causing anthracnose of tobacco. Mycological Research 105, 1340-1347. doi: $10.1017 / \mathrm{S} 0953756201005111$

Shen S, Goodwin PH, Hsiang T (2001b) Infection of Nicotiana spp by the anthracnose fungus, Colletotrichum orbiculare. European Journal of Plant Pathology 107, 767-773. doi: 10.1023/A:1012280102161

Solis C, Becerra J, Flores C, Robledo J, Silva M (2004) Antibacterial and antifungal terpenes from Pilgerodendron uviferum (D. Don) Florin. Journal of the Chilean Chemical Society 49, 157-162.

Stapleton A, Beetham JK, Pinot F, Garbarino JE, Rockhold DR, Friedman M, Hammock BD, Belknap WR (1994) Cloning and expression of soluble epoxide hydrolase from potato. The Plant Journal 6, 251-258. doi: 10.1046/j.1365-313X.1994.6020251.x

Szatmari A, Ott PG, Varga GJ, Besenyei E, Czelleng A, Klement Z, Bozsó Z (2006) Characterisation of basal resistance (BR) by expression patterns of newly isolated representative genes in tobacco. Plant Cell Reports 25, 728-740. doi: 10.1007/s00299-005-0110-5

Vidhyasekaran P (2008) 'Fungal pathogenesis in plants and crops.' (CRC Press: Boca Raton, FL)

Vranová VC, Atichartpongkul S, Villarroel R, Montagu MV, Inzé D, Wim Camp WV (2002) Comprehensive analysis of gene expression in Nicotiana tabacum leaves acclimated to oxidative stress. Proceedings of the National Academy of Sciences of the United States of America 99, 10870-10875. doi: 10.1073/pnas. 152337999

Xiao F, Goodwin SM, Xiao Y, Sun Z, Baker D, Tang X, Jenks MA, Zhou JM (2004) Arabidopsis CYP86A2 represses Pseudomonas syringae type III genes and is required for cuticle development. The EMBO Journal $\mathbf{2 3}$, 2903-2913. doi: 10.1038/sj.emboj.7600290

Yoshimoto K, Hanaoka H, Sato S, Kato T, Tabata S, Noda TD, Ohsumi Y (2004) Processing of ATG8s, ubiquitin-like proteins, and their deconjugation by ATG4s are essential for plant autophagy. The Plant Cell 16, 2967-2983. doi: 10.1105/tpc.104.025395

Manuscript received 4 June 2008, accepted 5 August 2008 